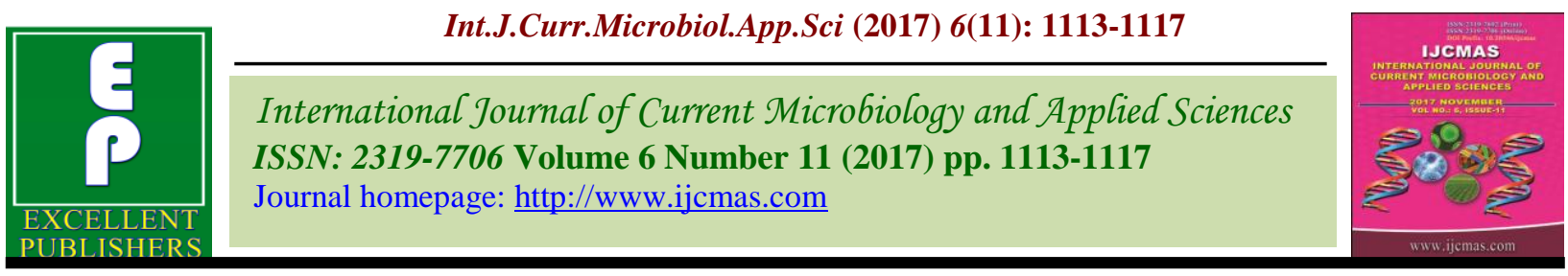

Case Study

https://doi.org/10.20546/ijcmas.2017.611.131

\title{
Hematobiochemical Alterations and Therapeutic Management of Puerperal Tetany in Bitch
}

\author{
Sheikh Tajamul Islam*, Mohd Younis Ganaie, Rayeesa Ali, \\ Syed Shakeebah Kubra and Anand Kumar
}

\author{
Department of Veterinary Medicine, International Institute of Veterinary Education and \\ Research (IIVER), Rohtak, Haryana-124001, India \\ *Corresponding author
}

\section{A B S T R A C T}

\section{Keywords}

Bellodona-30, Canine,

Calcium gluconate,

Puerperal tetany.

\section{Article Info}

Accepted:

10 September 2017

Available Online:

10 November 2017
A Pomeranian female dog four year old weighing $10 \mathrm{~kg}$ with litter size 5 puppies of Labrador mix, was presented to Sanjay Gandhi Animal Care Centre (SGACC) Rajouri garden New Delhi, India, with history of whelped 7 days back, lameness, hyperthermia, anorexia and restlessness. Clinical examination revealed pyrexia $\left(104.8^{\circ} \mathrm{F}\right)$, tachyponea $(50$ breaths/min), tachycardia ( 105 beats per minute), congested mucous membrane, hind limb muscle twitching, severe panting, ataxia and stiffness. The case was tentatively diagnosed as eclampsia on the basis of history and clinical signs which was later confirmed by hematology and electrolyte analysis. History also revealed that the main predisposing factors which cause eclampsia in dogs are poor management, poor nutrition, excessive milk production, increased litter size. The bitch was treated with, intravenous $10 \mathrm{ml}$ of $10 \%$ Calcium gluconate and Belladonna-30 orally along with supportive therapy which shows positive response to treatment and uneventful recovery 3 days after treatment.

\section{Introduction}

Eclampsia is an acute, life-threatening disease caused by low blood calcium levels (hypocalcaemia) in dogs and more rarely in cats (Pathan et al., 2011). There is lesser documentation of hypocalcaemia in dogs and cats as compared to cattle (Rowland et al., 1972). Canine Eclampsia more correctly called Puerperal Tetany is a startling and dangerous condition brought on by extremely low levels of calcium in the blood stream. It is sometimes erroneously called as milk fever. Low blood calcium is the result of reduction of calcium levels outside the cells of the bitch's body. The disease most commonly occurs in bitches 1-3 weeks after giving birth but the cases are also sometimes observed during gestation (Pathan et al., 2011). It may also occur occasionally during late pregnancy or at parturition (Catharina, 2005). As the demand for milk increases the possibility of eclampsia increases. Normally, by 40 days after whelping, the risk of eclampsia has passed. The pups of the affected bitches may not be usually affected as the affected bitches usually produce milk with normal calcium level. Lactating animals are especially susceptible to blood calcium depletion because of milk production. The body of some lactating dogs and cats simply cannot keep up with the increased demands for 
calcium. Imbalance between the rates of in flow and out flow from the extra cellular fluid calcium because of the increased loss into the milk appears to be an important factor in the pathogenesis of puerperal tetany in the bitches (Ettinger, 1983). Animals with puerperal tetany lack the ability to quickly move calcium into their milk without depleting their own blood levels of this mineral. Smaller breeds of dogs are more prone to the disease as compared to the larger breeds (Pathan et $a l .$, 2011). The disease has been reported to be more frequently observed in small, hyper excitable breeds of dogs. Eclampsia may not be necessarily associated with large litter size. Clinical course is too much rapid with initial signs restlessness, behavior changes, facial prurits, lameness, stiffness, poor mothering and ataxia (Skerrit, 1988). Eclampsia is also characterized by muscular tetany, convulsions, tonic-clonic seizures and death may occur within 12 hours in severe and nonresponsive cases. Eclampsia is a common emergency presentation for postpartum bitches in their first few weeks of lactation. Timely treatment is necessary to prevent death and is usually successful. Diagnosis is relatively easy with an accurate history and physical examination. Laboratory findings of hypocalcemia are characteristic, although recent information indicates that magnesium may also play a role. Treatment is readily administered in the practice setting, most bitches recover quite well with appropriate monitoring and continued therapy.

\section{History and Clinical Observations}

A Pomeranian female dog four year old weighing $10 \mathrm{~kg}$ with litter size 5 puppies of Labrador mix, was presented to Sanjay Gandhi Animal Care Centre (SGACC) Rajouri garden New Delhi, India, after 7 days of whelping. History revealed lameness, hyperthermia, anorexia, poor mothering and restlessness. Clinical examination revealed pyrexia $\left(104.8^{\circ} \mathrm{F}\right), \quad$ tachyponea $\quad(50$ breaths/min), tachycardia (105 beats per minute), congested mucous membrane, hind limb muscle twitching, severe panting, convulsions, ataxia and stiffness. On the basis of clinical examination tentative diagnosis was made. Confirmatory diagnosis was made on the basis of hemato-biochemical and serum mineral estimation which includes calcium, sodium, potassium, phosphorus and magnesium. Blood sample was collected on day 0 and 3 days after treatment in EDTA vacutainer for hematology and in red top vacutainer without anticoagulant for biochemistry and serum mineral estimation (Tables 1 and 2). In the present study it was found that no significant changes occur in hematobiochemical values except decrease in blood glucose level (73 mg/dl) and hypoalbuminia $(2.9 \mathrm{mg} / \mathrm{dl})$ while significant changes occurs in serum mineral concentration like hypocalcemia $(6.2 \mathrm{mg} / \mathrm{dl})$ and hypophosphetemia $(1.5 \mathrm{mg} / \mathrm{dl})$.

\section{Treatments and Discussion}

On the day of presentation of bitch treatment was started with management of hyperthermia with application of cold ice packs over ventral abdomen, paws and cold enema was given. After application of cold ice packs and cold enema the body temperature returned towards normal range $\left(102.5^{\circ} \mathrm{F}\right)$. When the body temperature returned to normal $10 \%$ calcium gluconate therapy was started administered intravenously@10 mL total dose slowly over a period of 40 minutes with regular monitoring of heart rate for tachycardia and bradycardia by auscultation of heart.

Glucose therapy was done with $100 \mathrm{~mL} 25 \%$ dextrose intravenously on day of presentation to hospital followed by $200 \mathrm{~mL} 5 \%$ glucose. Diazepam was also injected @ 0.5-2 mg/kg BW stat to control the seizures and convulsions followed by prescription of 
homeopathic Bellodona-30, 5 drops orally per day to further check the nervous signs. Owner was advised to give Calcium and vitamin D syrup@1tsf orally q 12 hours (Merical Pet) to prevent the reoccurrence of puerperal tetany after treatment. Dog owner has also been advised optimally, not to nurse puppies for at least the first 24 hours, but supplement them with calcium to decrease the demand for calcium and milk substitute. If signs relapse once puppies are returned to her remove puppies permanently from bitch. The bitch was recovered completely after three days of specific treatment along with supportive therapy and after three days blood parameters were within normal value.

Lactating small breeds of bitches, more susceptible to puerperal tetany, similarly reported by Pathan et al., 2011 and Alok et $a l ., 2017$. The clinical observations in the present study was in accordance with the Johnson et al., 2009. It was found that no significant change occurs in hematobiochemical parameters except decrease in blood glucose concentration and hypoalbuminia, similarly reported by Alok et al., 2017.

Table.1 Pre and Post treatment biochemical and electrolyte parameters of bitch affected with puerperal tetany

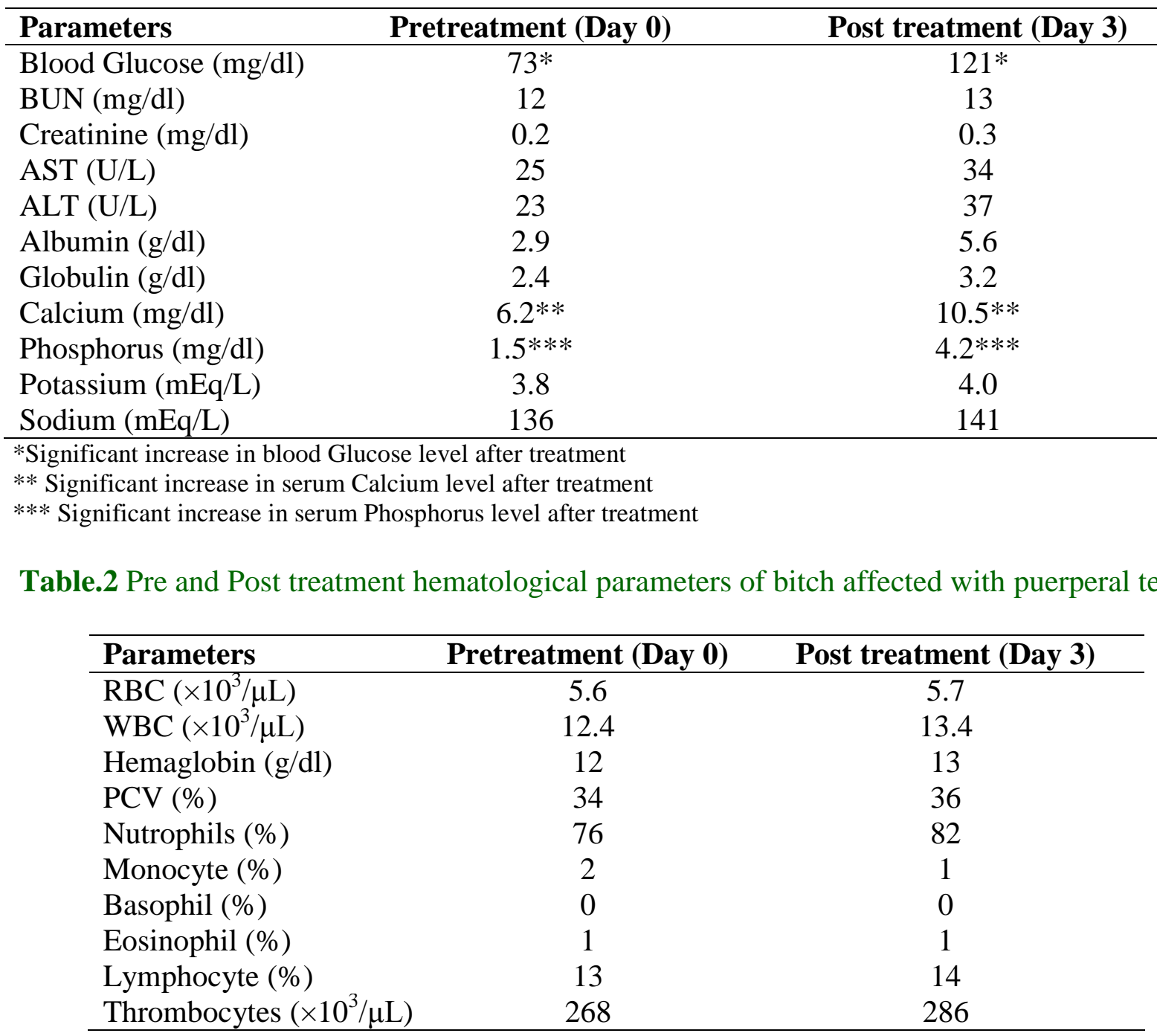


The concentration of serum calcium and phosphorus was found to be significantly decreased, these findings correlated with other authors who reported similar results Nelson et al., (2009) and Alok et al., (2017). Hypocalcemia causes hyperexcitibility of neuromuscular membranes, also reported by Gaschen et al., 1998. When the calcium ion concentration decreases, the neuronal memebrane permeability increases. The nerve fibres begin to discharge spontaneously initiating nerve impulses to peripheral skeletal muscles causes muscle fasciculation, similarly reported by Feldman et al., (2005).

Hypoglycemia was found in the present case which is accordance with Catharina et al., (2005). Decreased blood glucose level may be due to the increased muscular activity as a result of tetany. Hyperthermia was also found in this case which may be also due to increased muscular activity. This finding was similar to the observations of Alok et al., (2017).

Body is unable to cope up loss of calcium in milk during lactation due to inability of calcium hemostatic mechanisms and it is thought to be the cause of hypocalcemia associated with bitch during lactation period or nursing as also suggested by Aroch et al., (1999).

For successful treatment of the puerperal tetany the primary therapeutic approach is to restore the serum calcium level. Before calcium therapy $10 \%$ calcium gluconate administered intravenously @ $10 \mathrm{ml}$ total dose slowly over a period of 40 minutes with regular monitoring of heart rate for tachycardia and bradycardia by auscultation of heart, the primary step is the management of hyperthermia with cold enema and application of ice packs. Glucose therapy was done with $100 \mathrm{~mL} 25 \%$ dextrose $\left(\mathrm{D}_{25}\right)$ intravenously on day of presentation to hospital followed by $200 \mathrm{~mL} 5 \%$ glucose to check the hypoglycemia associated with hypocalcemia. Diazepam was also injected @ $0.5-2 \mathrm{mg} / \mathrm{kg}$ BW stat to control the seizures and convulsions. The above protocol gives fruitful results and after sometime bitch showed positive response to the remedy. Owner was advised to give Calcium and vitamin D syrup @ 1tsf orally q 12 hours (Merical Pet) to prevent the relapse of puerperal tetany and homeopathic Bellodona 5 drops orally per day to further check the nervous signs for ten days. Dog owner has also been advised optimally, not to nurse puppies for 24 hours which adjuvants our therapeutic protocol. Three days of posttreatment parameters were recorded again which showed normal parameters and the was clinically healthy.

\section{References}

Alok, K. C. Mukesh, S. Alok, S. and Ram, S. (2017). Clinical management of puerperal tetany in a bitch: A case study. Indian journal of veterinary Medicine. 9(1).

Aroch, I., Srebo, H., and Shpigel, N.Y., 1999. Serum electrolyte concentration in bitches with eclampsia. Vet Rec., 145:318-320.

Chatharina, L. F. (2005). Abnormalities in pregnancy, parturition and post parturient perios. In: Textbook Veterinary Internal Medicine (eds. S. J. Ettinger and E. C. Feldman. $6^{\text {th }}$ edition. W. B. Saunders, London. Pp. 16551667.

Ettinger, S. D. (1983). Textbook of Veterinary internal medicine-Diseases of dogs and cats, 2nd edn.,

Gaschen F.P. 1998. Disorders of Calcium metabolism in Canine medicine and Therapeutics. (ed. Neil. T. Gorman) $4^{\text {th }}$ Edn. Blackwell Science, U.K. Pp. 596603. 
Johnson, C.A. 2009. Postpartum and mammary disorders. In: Nelson, R.W., Couto, G.C., editors Small Animal Internal Mediocine. $5^{\text {th }}$ Edn. St. Louis: Mosby/Elsavier. USA. Pp. 944-949.

Nelson, R.W., 2009. Electrolyte Imbalances. In: Nelson, R.W., Couto, G.C., editors Small Animal Internal Mediocine. $5^{\text {th }}$ Edn. St. Louis: Mosby/Elsavier. USA. Pp. 864-883.

Pathan M. M. Siddiquee G. M. Latif A. Das
H. Khan Md. J. Z. and Shukla M. K. (2011). Eclampsia in a Dog: An Overview. Vet. World. 4(1): 45-47

Rowland, G. N. (1972). Microradiographic evaluation of bone from cows with experimental hypovitaminosis $\mathrm{D}$, diet induced hypocalcaemia and naturally occurring parturient peresis. Tissue Res. 9: 179.

Skerrit, G. (1988). Canine Epilepsy. In practice. $10(1): 27-30$.

\section{How to cite this article:}

Sheikh Tajamul Islam, Mohd Younis Ganaie, Rayeesa Ali, Syed Shakeebah Kubra and Anand Kumar. 2017. Hematobiochemical Alterations and Therapeutic Management of Puerperal Tetany in Bitch. Int.J.Curr.Microbiol.App.Sci. 6(11): 1113-1117. doi: https://doi.org/10.20546/ijcmas.2017.611.131 